\title{
CAMBIASSU

\section{Necropolítica e ds imagens da morte no filme a gente se vê ontem (2019)}

\section{Necropolitics and images of death in the film see you yesterday (2019)}

\section{Josué Victor dos Santos Gomes}

Mestrando em Comunicação Social no PPGCOM UFMG com bolsa CAPES-Proex. Atualmente, integra o Insurgente: Grupo de Pesquisa em Comunicação, Redes Textuais e Relações de Poder/Saber e grupo Coragem UFMG. Tem interesse de pesquisa em Afrofuturismo, Cinema Negro e Cinema Brasileiro. Contato: josuevictordossantos@rgmail.com

\section{Carlos Alberto de Carvalho}

Professor Associado do Curso de Comunicação Social da Universidade Federal de Minas Gerais, na graduação e no programa de pós-graduação. Doutor (2010) em Comunicação Social pela UFMG. Pós-doutorado realizado na Universidade do Minho, Portugal, com bolsa Capes (Processo: CAPES/FCT no 9680/14-4). Contato: carloscarvalho0209argmail.com

\section{Verônica Soares da Costa}

Professora no curso de Jornalismo da PUC Minas. Jornalista, graduada em Comunicação Social pela Universidade Federal de Juiz de Fora (UFJF - 2007), Mestre em História, Política e Bens Culturais pela FGV (2011) e doutora em Textualidades Midiáticas pelo PPGCOM UFMG (2019). Contato: ve.scosta@ıgmail.com 


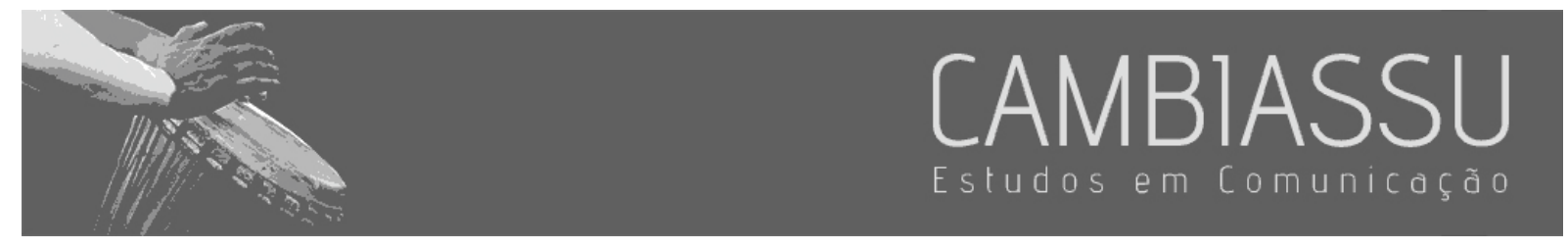

\section{Resumo}

O presente artigo reflete os conceitos de necropolítica (MBEMBE, 2017) e wake-work (SHARPE, 2016) partindo do filme $A$ Gente Se Vê Ontem (2019). Através da análise interpretativa das cenas de assassinato e da aproximação com os conceitos revisados, entendemos que a obra utiliza múltiplas visualidades da morte para construir uma ambientação necropolítica. Vislumbramos que a necropolítica se apresenta no filme como uma condição perturbadora da habitação das personagens no tempoespaço, assim como também afeta as vivências negras no mundo em que compartilhamos.

Paldvras-chave: cenas de morte; cinema; necropolítica; racismo; temporalidade.

\section{Abstract}

This article reflects the concepts of necropolitics (MBEMBE, 2017) and wake-work (SHARPE, 2016) based on the film See You Yesterday (2019). Through the interpretive analysis of the murder scenes and the approach to the revised concepts, we conclude that the work uses multiple visualities of death to build a necropolitical setting. We glimpse that necropolitics appear not to film as a disturbing condition of the room of personagens not time-space, as well as it also affects black lives in the world in which we share.

Keywords: death scenes; movies; necropolitics; racism; temporality. 


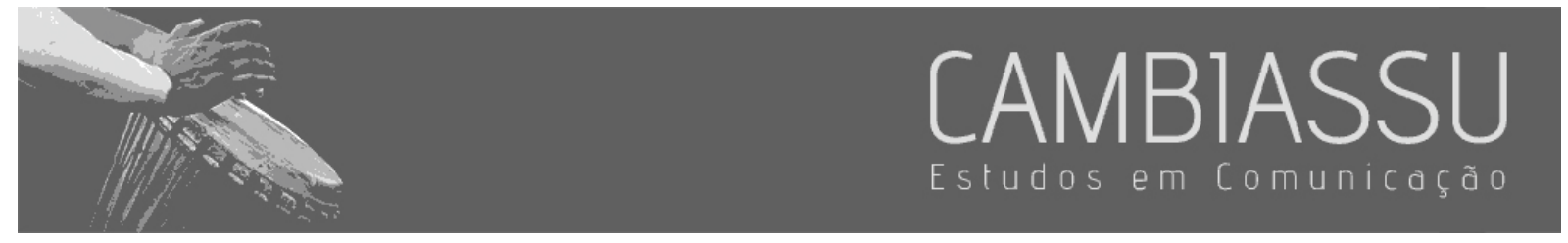

\section{1 lntrodução}

A escravidão, formalmente extinguida, permanece viva através das consequências por ela deixada, como o engendramento do genocídio negro em vários países pós-coloniais. Almeida (2019) alerta-nos que o racismo é histórico e estrutural, resultando em agências institucionais e pessoais que perpetuam as desigualdades. Nossas sociedades possuem mecanismos que desumanizam os corpos negros e permitem que sejamos mortos de diferentes maneiras. Essa realidade manifesta-se em acontecimentos, mas também ocupa o imaginário nas ficções, filmes, livros e histórias. Através dessas narrativas, podemos mobilizar novos entendimentos sobre o racismo e a presença da morte no cotidiano das diásporas. Um exemplo disso é o filme $A$ Gente Se Vê Ontem (2019), da Netflix.

O filme, de título original See You Yesterday, é dirigido por ALZAMORA, Geane. Textualidades Midiáticas. Belo Horizonte: PPGCom/UFMG, 2018. p. 103-112. Bristol e tem como produtor executivo o cineasta Spike Lee. Lançado mundialmente em 17/05/2019, a história acontece na região novaiorquina do Brooklyn e tem como protagonistas uma dupla de estudantes negros no segundo ano do ensino médio da Escola de Ciências do Bronx. Claudette Josefine e Sebastian são dois melhores amigos muito talentosos no mundo das ciências e possuem o objetivo de construir uma Mochila de Deslocamento Temporal (MTD) para viajar ao passado. Quando o irmão mais velho de CJ, Calvin, é assassinado injustamente pela polícia, a dupla assume a missão de aprimorar cada vez mais a máquina para voltar ao passado e tentar evitar a tragédia. A partir desse momento, o filme é tomado pelas diversas tentativas que eles realizam e fracassam, pois sempre que os dois voltam ao dia do assassinato, em 04/07/2019, um empecilho se manifesta, fazendo com que Calvin ou outra pessoa negra seja assassinada em seu lugar.

A Gente Se Vê Ontem (2019) pode ser considerado um filme que está inserido dentro do movimento estético e político do afrofuturismo, tendo em vista que a obra mobiliza elementos especulativos para lidar com questões de conflito racial. O longa-metragem possui a presença de 


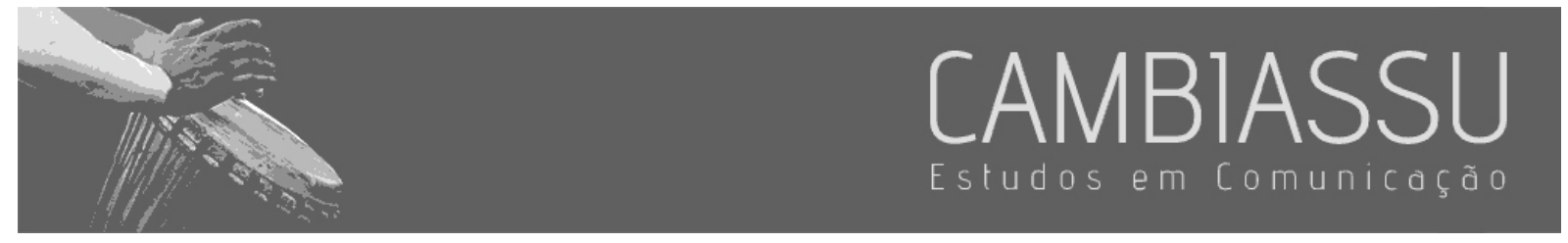

pessoas negras utilizando da ciência e tecnologia para realizar uma discussão sobre o racismo e sobre a violência policial no contexto estadunidense. Isso é perceptível através das distorções temporais que são acionadas pelo dispositivo da viagem no tempo e na proposta de uma não linearidade temporal que possibilita às personagens alterarem as consequências do futuro no passado e no presente.

Apesar do conceito de afrofuturismo não ser o foco central do artigo, consideremos importante constatar a concepção do pensador Eshun (2015). Para o autor, as obras do afrofuturismo tem a capacidade de apresentar contradições e invenções que demonstram como a experiência da negritude é atravessada por temporalidades e espacialidades diferentes das propostas lineares que são atribuídas pela modernidade e pelo capitalismo. Eshun (2015) acredita que as diversas fabulações que provocam horror, medo, pânico e sublimação presentes nas ficções científicas (ex: abdução, monstros e violências) são equiparáveis às condições de extermínio que o racismo historicamente impõe aos negros, pois "[...] a ficção científica, como tal, é reformulada à luz da história afrodiaspórica" (ESHUN, 2015, p. 57). Nesse sentido, temos a intenção de realizar uma leitura de nosso fenômeno ficcional considerando suas invenções científicas, fabulações e conflitos raciais como metáforas para condição que a população negra, afro-americana ou não, experimenta no mundo extra tela.

Em suma, temos como objetivo entender como o longa-metragem $A$ Gente Se Vê Ontem (Stefon Bristol, 2019) pode ter suas construções imagéticas e a estrutura narrativa interpeladas pelos conceitos de necropolítica (MBEMBE, 2017) e wake-work (luto-vigília) (SHARPE, 2016), suscitando reflexões sobre as dinâmicas raciais contemporâneas. Através da análise das cenas que sintetizam o homicídio das personagens negras, refletimos acerca das visualidades da morte construídas no filme, sobre a relação e importância que estas visualidades ocupam na narrativa e de que maneira o filme se aproxima da realidade social de sujeitos negros em nossas sociedades.

\section{As relações raciais de inimizade e a necropolítica}




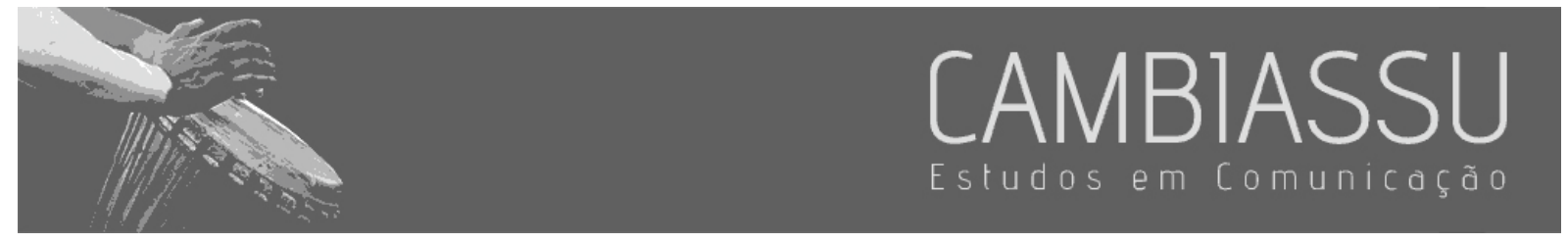

A raça como uma categoria social de subalternização tem sua origem apontada por diversas áreas das ciências humanas a partir do século XVI, no início do processo de colonização das Américas. Nesse período, a raça tem a função de justificar a exploração de corpos e territórios africanos para iniciar o processo de escravização - principalmente pelas nações da Europa. Segundo Almeida (2019), o início do pensamento que possibilita a classificação e hierarquização de pessoas/culturas se dá a partir das navegações europeias e do desenvolvimento do mercantilismo.

Com a chegada das transformações do lluminismo em 1715 d.C., o homem europeu torna-se o centro do pensamento cultural e científico das sociedades, o que impulsiona as reformulações das instituições sociais com o objetivo de torná-las cada vez mais racionais e laicas. O europeu coloca-se como referência de desenvolvimento cultural, psicológico, científico e nas demais categorias que podiam medir a excelência de suas ações. Partindo dessa autoficção, os sujeitos brancos passam a se confrontar com as diferenças e produzir a raça como a condição de inferiorização para classificar aqueles com que não partilham do continente e do capital cultural cristão/ocidental.

Achille Mbembe afirma que "[...] a raça não existe enquanto facto natural, físico, antropológico ou genético" (MBEMBE, 2014, p. 26). Dessa forma, a colocação da raça enquanto uma tipificação que media as relações parte de um alterocídio em que o outro não é visto como semelhante a si mesmo e que, portanto, não possui direito de partilhar de uma igualdade de existência em direitos. A imposição dessa subalternidade atribuída aos fenótipos e pela diferença cultural é motivada por conflitos de posse de bens (disputa de classe) e de liberdade (gênero). O corpo negro racializado no período da escravização se transforma em mercadoria, em uma matéria de inexistência acumulativa da qual se extrai a exploração corporal e mental na busca de enriquecer os impérios europeus ${ }^{1} \mathrm{e}$ as colônias que

\footnotetext{
1 Não entraremos aqui na questão da escravidão encabeçada pelos povos árabes tendo em vista que nosso objeto de pesquisa se localiza na consequência do racismo os Estados Unidos, uma ex-colônia de povoamento britânica. Contudo, algumas reflexões sobre o modus operandida racialização podem ajudar a entender como a corrupção da humanidade permite que esses regimes de exploração se estabeleçam.
} 


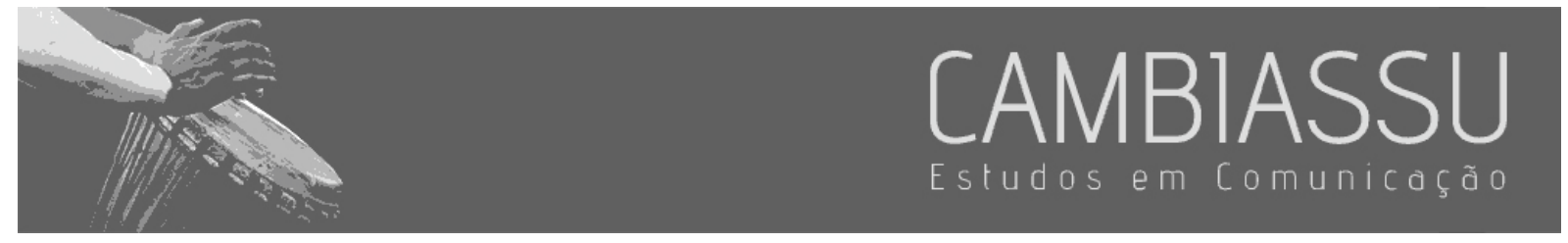

conquistaram sua independência. Em nome de um pré-capitalismo, essa estrutura lapidou e minerou a humanidade do negro para transformá-lo em uma figura fora de si, dita pelo e para o outro.

Mbembe (2017) identifica, nesse contexto, a condição histórica que foi capaz de gerar sociedades e nações suplantadas pelo terror e pela morte, nomeando essa organização sociopolítica de necropolítica. Através de uma análise sobre o uso da morte operacionalizada pelos Estados com o objetivo de exercer a soberania, o filósofo evidencia que as colônias escravagistas são territórios que sempre estiveram sob a égide de um estado de sítio e exceção. Por estarem fora da Europa, o entendimento de guerra justa e o reconhecimento do uso da força por motivações políticas era inexistente nas colônias. Na ausência de um tratado de respeito mútuo no qual as nações e corpos se reconheçam em estado de guerra ou de paz, resta às colônias e aos seus habitantes a condição de existência sob o caos, sobretudo, na força bélica sem precedentes direcionada aos corpos racializados.

Para Mbembe (2017), o exercício da soberania depende diretamente da produção de uma noção ficcional de inimigo ou de perigo iminente. Assim, qualquer ameaça que venha desestabilizar o grau e a direção do exercício do biopoder na visão foucaultiana, ou seja, "[...] a divisão das pessoas que têm que morrer e que têm que viver" (MBEMBE, 2017, p. 116), é encarada como uma ameaça em potencial. Nesse sentido, podemos afirmar que a agência das instâncias institucionais do estado como a polícia e o sistema jurídico influencia e reitera práticas de relações de inimizade.

Assim sendo, "[...] a percepção do Outro como um assalto à minha vida, como uma ameaça mortal ou um perigo absoluto, cuja eliminação biofísica pudesse fortalecer minha possibilidade de vida e segurança [...]" (MBEMBE, 2017, p. 117) direcionava o necropoder em sua face estatal e personificada aos corpos negros escravizados e atualmente sacrifica seus descendentes e aqueles que desafiam as hegemonias herdeiras da escravidão.

Segundo o observatório de morte provocada por tiroteios policiais do jornal The Washington Post, nos EUA, país em que se passa o filme analisado, embora metade das pessoas fatalmente 


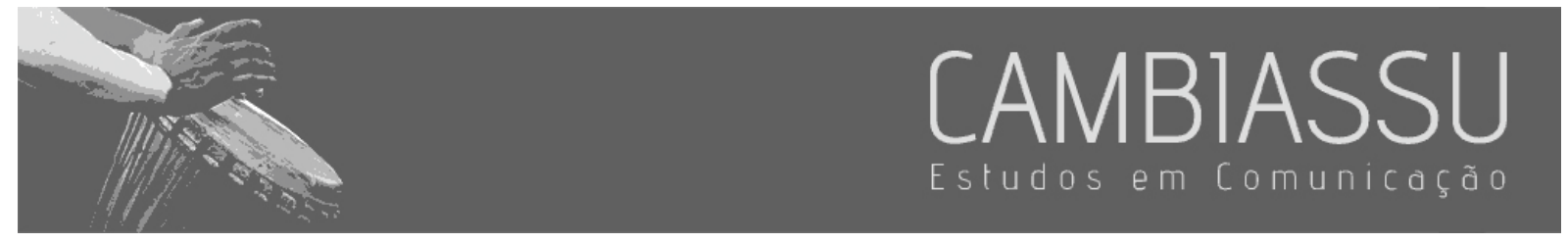

baleadas pela polícia entre 2015 e 2020 fosse branca (2.721), na proporção da quantidade de habitantes racializados no país fica evidente o número desigual entre as mortes. A população branca representa $60 \%$ (197M) do total de habitantes dos EUA, já a população negra representa $13 \%(42 \mathrm{M})$. A taxa de mortalidade por violência policial da população negra é de 34 por milhão, enquanto a da população branca é de 14 por milhão, ficando, ainda, atrás da população hispânica, que possui a taxa de 25 por milhão e representa $11 \%$ do total de habitantes (39M). Além disso, segundo a organização Sentencing Project, a população carcerária dos EUA em 2020 é de 2.200.000, 67\% (1.474.000) são pessoas não brancas, apesar do fato de que o nível habitacional da população racializada representa apenas $37 \%$ da população.

\section{As imagens da morte}

Quando o contexto violento provocado pela necropolítica e pelo racismo é retratado nas narrativas audiovisuais, temos em mãos a oportunidade de realizar novas leituras de mundo e ampliar nosso entendimento acerca dessas opressões. Para compreender as visualidades da morte negra, acionamos o conceito de "wake work", de Sharpe (2016)2, traduzido por Freitas e Souza (2018) como Iuto-vigília. Sharpe (2016) utiliza a polissemia da palavra wake para entender que a vida negra é um contínuo morrer, dessa forma:

[...] como substantivo pode ser uma vigília, mas também o rastro deixado por um navio na água, uma esteira, um sulco, um vestígio; como verbo, pode ser: velar, vigiar, fazer vigília, mas também acordar, despertar, reviver, ressuscitar tanto fisicamente (um corpo que desperta), quanto espiritualmente (tomar consciência). (FREITAS; SOUZA, 2018, p. 47)

Através de suas memórias pessoais sobre os encontros com a morte de familiares por consequências de adoecimento por condições precárias de trabalho e da violência policial, Sharpe

2 O conceito é apresentado no livro síntese da pesquisa da autora "In The Wake On Blackness and Being” (2016) 


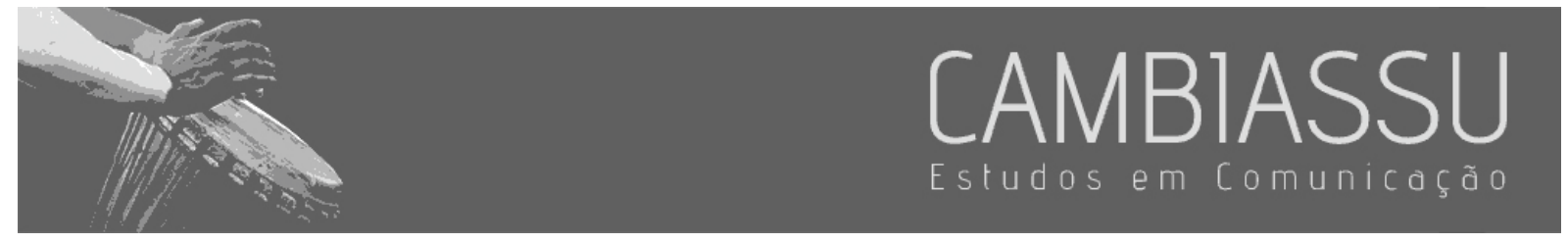

(2016) tece suas reflexões sobre como as experiências temporais dos negros são estruturadas pelo racismo através de uma circunscrição pela morte. Traçando uma análise sobre os recorrentes e diferentes encontros com a morte que a população negra mundial enfrenta desde o colonialismo, a autora explana que "[...] na esteira (in the wake), o passado que não é passado reaparece, sempre, para romper o presente" (SHARPE, 2016. p. 15). Nesse sentido, a Sharpe considera que a população negra estadunidense, mas também as populações negras ex-escravizadas e globalmente inseridas em uma economia de subalternidade, ainda experimentam as sujeições à morte e não pertencimento territorial da escravidão, que, embora sejam diferentes, permanecem deturpando a condição social dos sujeitos negros.

Partindo dessa perspectiva, Sharpe (2016) reconhece que as vivências negras contemporâneas no rastro/sulco/esteira da escravidão são a condição existencial do sujeito diaspórico e africano. Olhando para o significado de "wake" como o movimento de acordar ou assumir uma postura vigilante, ela considera que a negritude "[...] é ocupar e ser ocupado pelo presente contínuo e mutável da escravidão que ainda não foi resolvida" (SHARPE, 2016. p. 18). Esse trabalho (work) de sobreviver ao racismo e se manter vigilante às suas manifestações necropolíticas pode ser visto como a consciência de estar dentro desta cicatriz social. Em sua pesquisa, Sharpe (2016) busca entender e refletir sobre essa temporalidade mista na qual a antinegritude emerge nos desastres e mortes do cotidiano. Seu esforço está em busca de entender "[...] o que, se é que sobreviveu a essa insistente exclusão negra, e como a literatura, a performance e a cultura visual observam e mediam essa in/sobrevivência" (SHARPE, 2016. p. 18).

Ao se voltar para as obras que retratam o genocídio negro, Sharpe (2016) propõe que a produção artística e intelectual negra pode e precisa ser vista como corpus para que possamos entender as condições do racismo contemporâneo, sobretudo nas imagens em que a morte de pessoas negras toma a tela. A autora volta seu olhar investigativo para as culturas expressivas negras: 


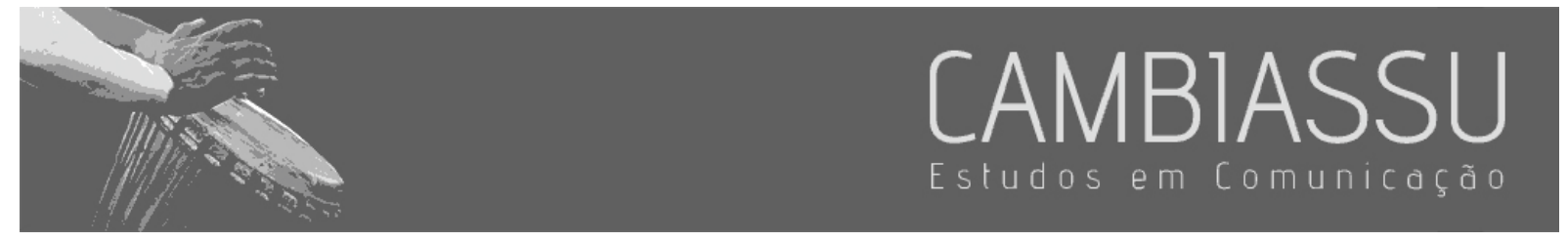

[...] que não buscam explicar ou resolver a questão desta exclusão em termos de assimilação, inclusão ou direitos civis ou humanos, mas sim retratar esteticamente a impossibilidade de tais resoluções, representando os paradoxos da negritude dentro e depois dos legados da negação da escravidão da humanidade negra. (SHARPE, 2016. p. 18).

Sendo assim, a partir das narrativas construídas por pessoas negras, nas quais a temática da negritude e do racismo são interseccionadas com a morte, podemos vislumbrar alfabetos da sobrevivência negra diaspórica e continental. Mas também é preciso se atentar ao tom denunciativo dessas imagens e às estratégias narrativas utilizadas para mobilizar essas visões, pois, não são raras as vezes em que a cultura cinematográfica escancara de forma desumana morte de negros estetizando a violência em detrimento da reflexão crítica.

A pensadora afro-americana hooks ${ }^{3}$ (2019) lembra-nos que a forma como as imagens de pessoas negras é acionada no cinema contribui para a construção do imaginário social e afetivo que a elas serão atribuídas. Segundo a autora, "[...] da escravidão em diante, os supremacistas brancos reconheceram que controlar as imagens é central para a manutenção de qualquer sistema de dominação racial” (hooks, 2019, p. 33). Nessa direção, é preciso sempre lançarmos mão de um olhar crítico às obras que enunciam o genocídio da população negras, pois a estetização da morte explícita do corpo negro nas imagens pode provocar dores, tendo em vista que estas estão diretamente ligadas ao mundo extra diegético. Nas redes sociais, jornais, revistas e diversas mídias a circulação de imagens de pessoas negras em condição de sofrimento ressaltam que a condição necropolítica da violência faz parte de um cotidiano que está para além da ficção.

Dessa maneira, é preciso avaliar a forma que os assassinatos de pessoas negras são narrados, quais recursos sonoros, visuais e gráficos são utilizados para construir essa morte e qual função o

\footnotetext{
${ }^{3} \mathrm{~A}$ autora pede que a grafia de seu nome seja feita em letras minúsculas.
} 


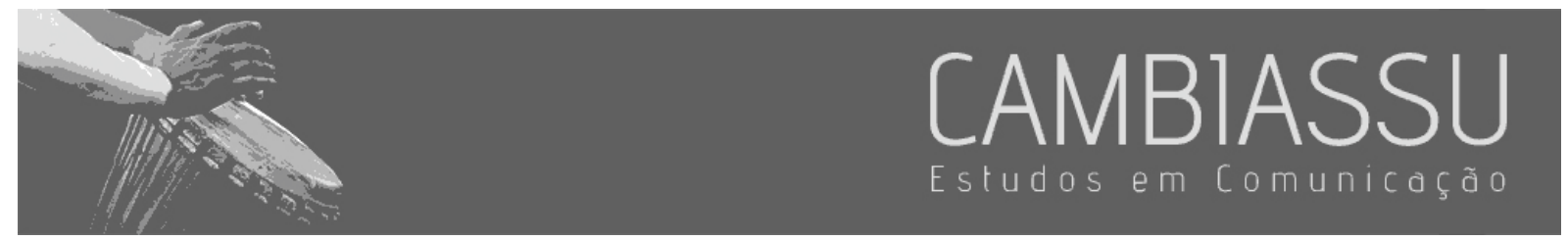

extermínio de um personagem negro ocupa dentro da história do filme. Em nossa concepção, mesmo em filmes dirigidos por pessoas negras, o olhar crítico faz-se necessário para que possamos evitar banalizar a violência que as imagens da morte negra podem gerar. Conforme nos lembra hooks (2019), os filmes e produções midiáticas "[...] determinam como a negritude e as pessoas negras são vistas e como outros grupos responderão a nós com base nas suas relações com a construção e o consumo de imagens" (hooks, 2019, p. 33). Sendo assim, acreditamos que a produção cinematográfica tem o dever ético de explorar as multiplicidades da linguagem para que a introdução da morte de pessoas negras nos roteiros não alimente o imaginário racista e reforce a noção de que as vidas negras são descartáveis.

\section{Localizações teórico-metodológicas}

Filiamo-nos ao posicionamento teórico e metodológico que compreende as imagens fixas, textos verbais, os produtos audiovisuais e demais fenômenos de pesquisa através da noção de textualidade. A textualidade pode ser entendida como um conjunto de processos comunicacionais e pragmáticos que "[...] desestabilizam as relações temporais e de sentido que definiriam a princípio os limites e os contornos dos textos" (LEAL, 2018, p. 23). Sendo assim, um texto, em outras palavras, um produto comunicacional ou ação humana, não é experienciado e nem observado em sua forma pura, mas é constituído por múltiplas linguagens (visuais, verbais, sonoras, grafias...) e ganha forma através das relações que estabelece com outros textos aos seu redor, por meio dos movimentos de reapropriação, contaminação, dominação, diálogo, reapropriação. Leal (2018), partindo das contribuições fundantes de Abril $(2007,2014)$, afirma que essas relações podem ser vistas tanto na forma entre macro/micro dentro de um mesmo contexto de produção, em nosso caso, por exemplo, cinema/filme, filmes/ficção, filme/cena, mas também pode ser apontada na ordem comparativa entre signo a signo. 


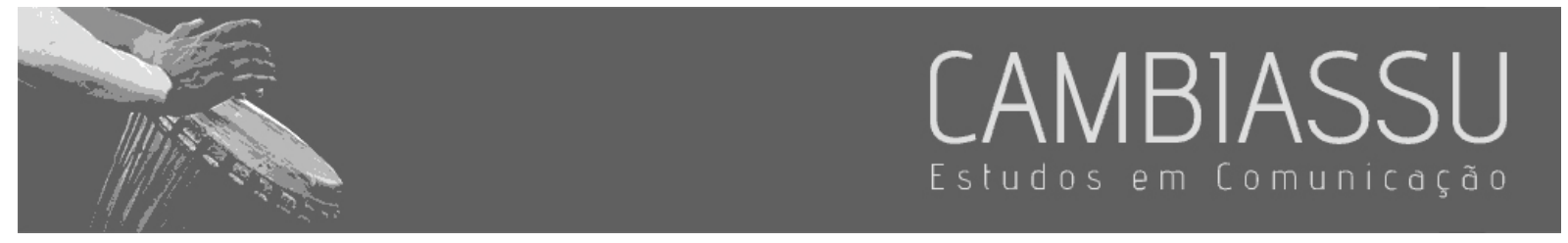

De acordo com Leal e Mendonça (2018), a imagem entendida como texto visual na visão de Abril (2012) abarca mais do que é visto pelos olhos, mas também diz respeito às suas marcas temporais, sociais e culturais que nela pode ser percebida. A representação visual não é vista como a reprodução de um mundo dado e estável, mas é entendida como uma ação produtora de sentidos, pois:

[...] como um acontecimento, a representação, em sua dimensão performativa, atua sobre a realidade social, sendo simultaneamente resultado de uma "imaginação criadora" e oferecendo-se como elemento a partir do qual outras criações se darão. (LEAL; MENDONÇA, 2018, p. 107)

Nesse sentido, a representação não trabalha na ordem de fazer reflexo de algo que está dado fora da imagem, em um suposto mundo real, mas sim tem capacidade de fazer ver o que não está lá. A imagem é capaz de criar e remodelar esse mundo. Dessa forma, as imagens não são geradas apenas através da repetição/reprodução de signos, mas também na capacidade de gerar novas relações de sentido, signos, imagens, em suas potências criativas.

$\mathrm{Na}$ seção seguinte, analisaremos as cenas e sequências nas quais a morte de alguma personagem negra é o principal acontecimento visualmente representado. Além das imagens, levamos em consideração os sons, atuações e a condução da sequência narrativa nas cenas. Buscamos identificar quais e como os recursos da linguagem cinematográfica construíram as imagens da morte, seja esta a representação da morte física, simbólica, sentimental ou outras dimensões que convocam o sentido de perda da vida, do corpo e do tempo.

\section{Análises}

Figura 1 - PRIMEIRA VISUALIZAÇÃO DA MORTE 

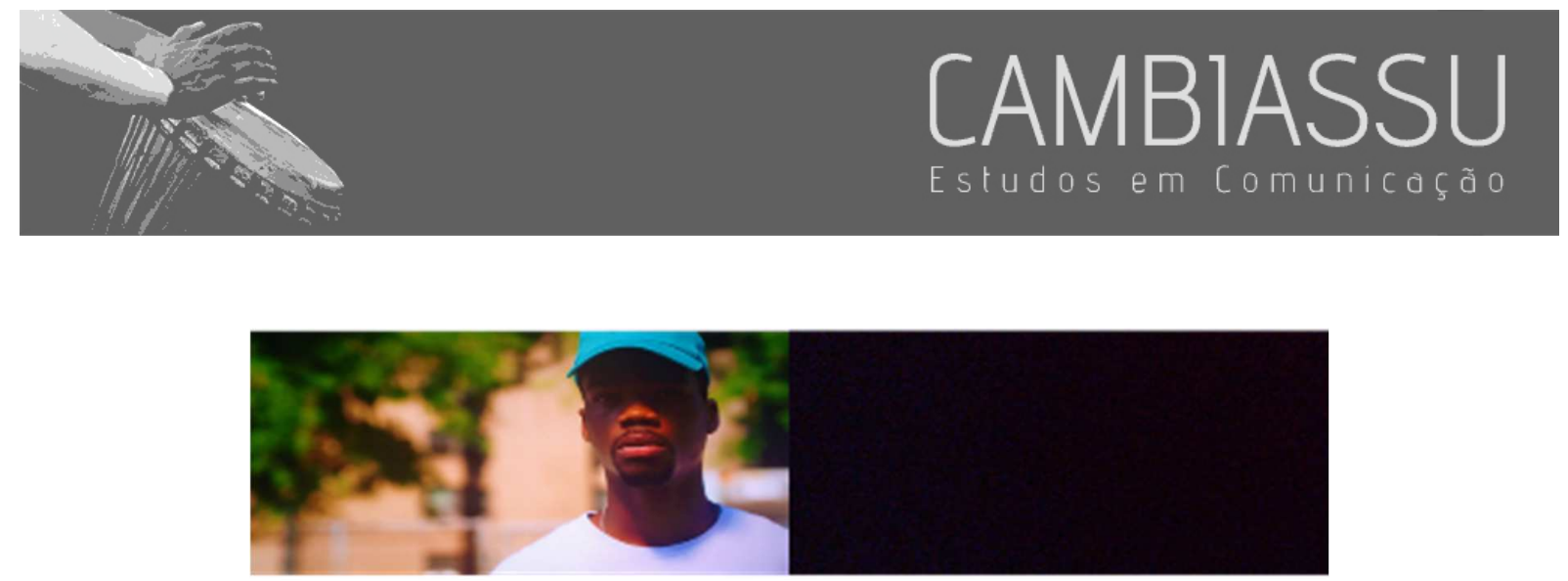

Fonte: A Gente Se Vê Ontem (Stefon Bristol, 2019, Netflix).

Na primeira vez que Calvin é assassinado, a morte é construída através da indução de sentidos, pois não é mostrado seu corpo sendo baleado ou caindo no chão. As imagens que vemos são de seu olhar encarando o policial que empunha a arma e, em seguida, somos levados a um fade preto (timecode: 30:52) que pode ser observado na imagem acima. Quando a câmera encara o olhar de Calvin em um movimento de zoom in, o som ambiente é substituído por algo parecido com uma buzina de trem crescente. Essa montagem trabalha com a morte a partir da suposição, convoca quem assiste a deduzir o que acontece em uma abordagem policial a partir das referências que são dadas nas cenas de protesto e abordagens policiais no início do filme, mas se completa com as vivências e conhecimentos sobre a violência policial por parte de quem assiste.

Figura 2 - SEGUNDA VISUALIZAÇÃO DA MORTE

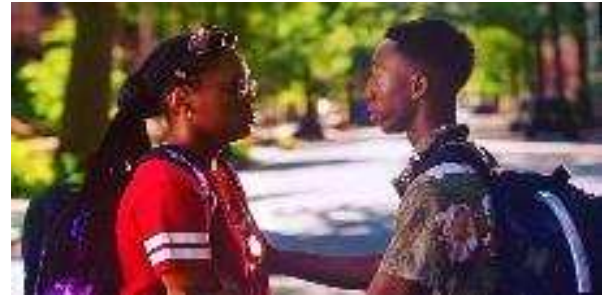

Fonte: A Gente Se Vê Ontem (Stefon Bristol, 2019, Netflix).

A segunda cena de morte ocorre na primeira tentativa de voltar no tempo para impedir o assassinato de Calvin. O plano de Claudette e Sebastian falha porque a dupla atrasa após serem perseguidos pelo ex-namorado de CJ em uma prática de bullying com a dupla. No momento aproximado de 00:43:40, ao ouvir o disparo da arma que mata Calvin, os viajantes do tempo percebem que já era tarde. A dimensão que é apresentada neste segundo homicídio é a da morte como a experiência da perda, sendo vista pelo corpo do outro que permanece vivo. Além da indução do som 


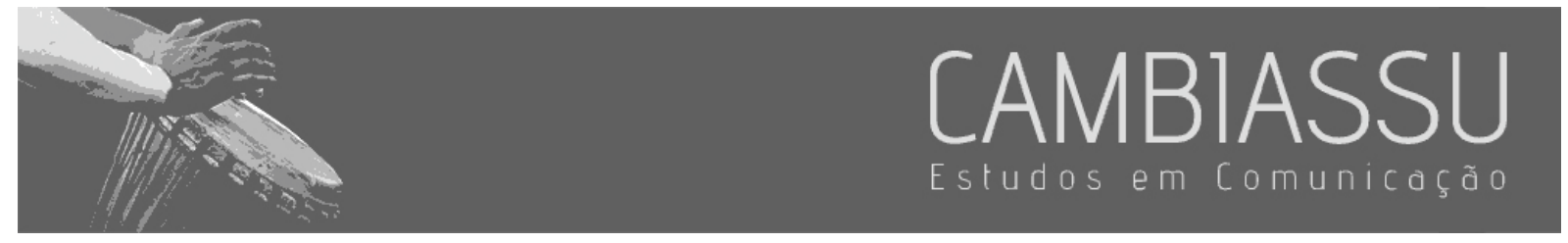

que anuncia o tiro, o que é trazido para cena é a reação emocional e física de dois jovens que naquele momento revivem a certeza da morte de Calvin.

Figura 3 - TERCEIRA VISUALIZAÇÃO DA MORTE

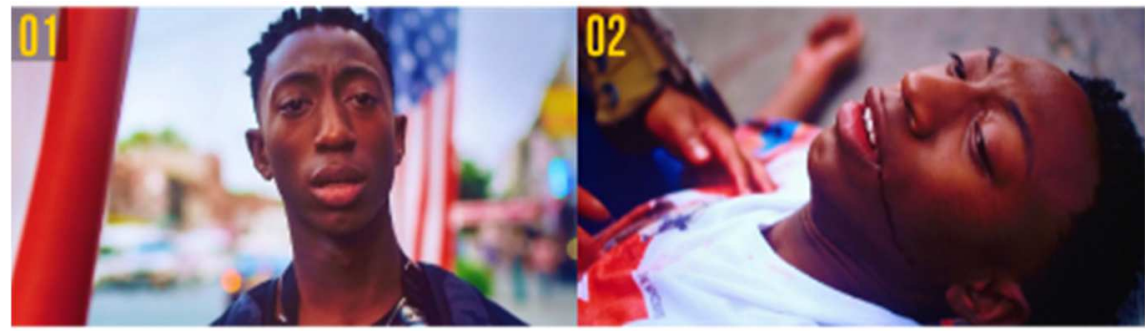

Fonte: A Gente Se Vê Ontem (Stefon Bristol, 2019, Netflix).

A terceira cena de morte ocorre durante a segunda tentativa de impedir o assassinato de Calvin.

Nesta ocasião, o plano da dupla é atrair a polícia até o local do assalto que desencadeia a abordagem de Calvin dez minutos mais cedo, mas a polícia não aparece. Então, CJ decide que ela avisaria o dono da loja sobre o roubo. A crise se inicia quando a versão de Sebastian, que vivia no passado do dia do assalto, vê CJ entrando na loja e a segue. Mesmo CJ conseguindo avisar o lojista, a reação do homem de empunhar uma arma e expulsar os dois suspeitos cria o clima de tensão. Como os dois assaltantes estavam armados, Carlito, o dono da loja, desiste de impedir o roubo. Além do dinheiro, eles tentam pegar a MDT das costas de CJ, o que leva a versão do passado de Sebastian discutir com os dois assaltantes e ser baleado.

O disparo novamente não é mostrado, apenas o ouvimos. A imagem mostrada é a visão do Sebastian do futuro no lado de fora da loja em uma câmera subjetiva. O garoto observa sua versão do passado sair andando de costas e caindo no chão. No momento em que o Sebastian do futuro encara a sua própria morte, o movimento de câmera de zoom in é novamente executado e deixa em close o rosto assustado do garoto - como vemos no frame 01 da figura 3, no minuto 00:55:04. Pela primeira vez a imagem do corpo negro violentado é trazida em cena. No frame 02 da figura 3 , temos um plano fechado da versão de Sebastian do passado com sangue saindo pela boca (timecode: 00:55:18). Este plano parece convocar a mesma função de mostrar como o personagem encara sua 


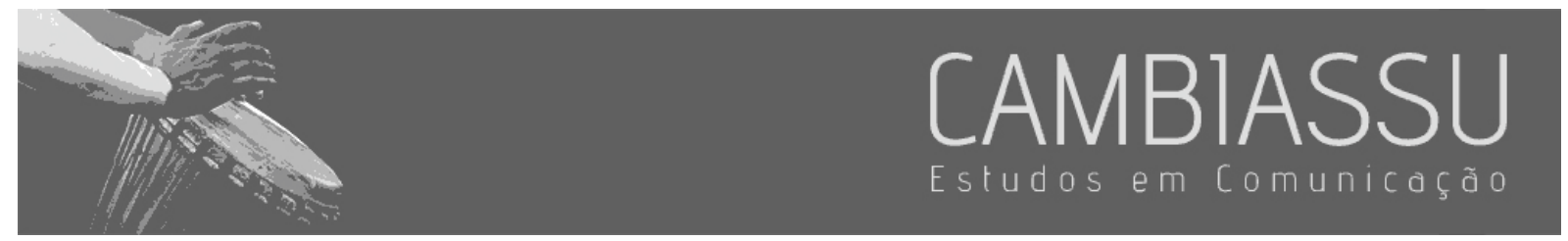

morte. Apesar de ter levado um tiro e estar agonizando, o olhar de espanto do Sebastian do passado é direcionado à sua versão futuro. Nesse sentido, para as duas versões do garoto, encarar a si equivale a encarar a personificação da morte. A vulnerabilidade do corpo violentado é expressa em duplo.

Figura 4 - QUARTA VISUALIZAÇÃO DA MORTE

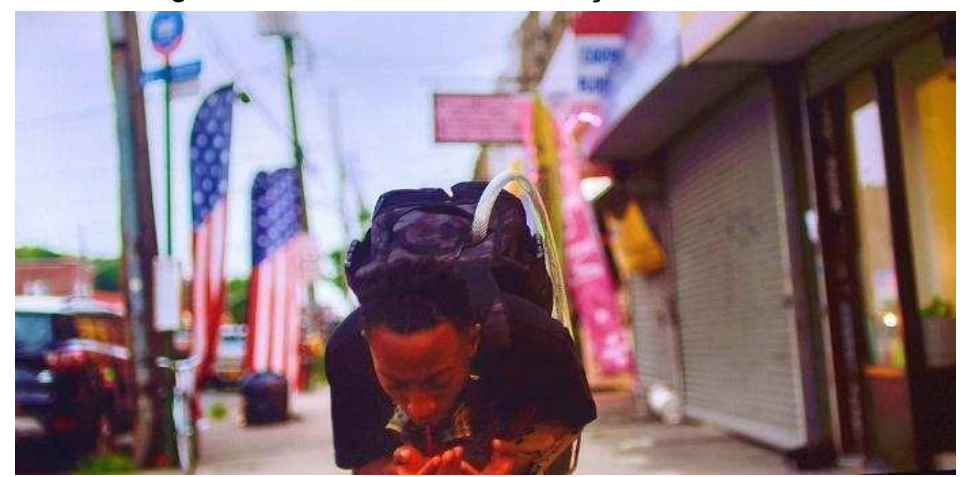

Fonte: A Gente Se Vê Ontem (Stefon Bristol, 2019, Netflix).

Depois que o Sebastian do passado de fato morre na linha do tempo do dia 04/07/2019, sua versão do futuro colapsa. Sem nem mesmo ser alvo direto de alguma violência, seu corpo se curva e sangra pela boca igual ao corpo de seu passado, como podemos ver acima, no momento aproximado de 00:55:26. Após essa reação, seu corpo falha como uma imagem holográfica com defeitos e deixa de existir por inteiro. Temos nesta sequência duas formas explícitas de construção da morte, pois são duas pessoas que perdem a vida em uma reação em cadeia, mesmo diante do fato de que os dois constituem o mesmo ser. Nesse sentido, a dimensão da perda sentida por CJ também é dupla, pois ela tem contato direto com as duas versões de seu companheiro que agonizam sem que ela consiga evitar.

A incapacidade/impossibilidade de $\mathrm{CJ}$ de lidar com todos esses lutos é facilmente percebida em seu fôlego extremo em continuar aprimorando a MTD em busca de impedir o assassinato de uma vida em sua rede afetiva. Dessa forma, a terceira tentativa ocasiona a quinta cena mórbida presente no filme. Em sua quarta viagem, CJ assimila sua versão da viagem 03 e retorna ao momento em que ela e Sebastian haviam chegado, como se a viagem não tivesse sido feita. Sem dar explicação ao amigo, ela muda o plano de chamar a polícia e segue correndo para a rua Malcom X para convencer 


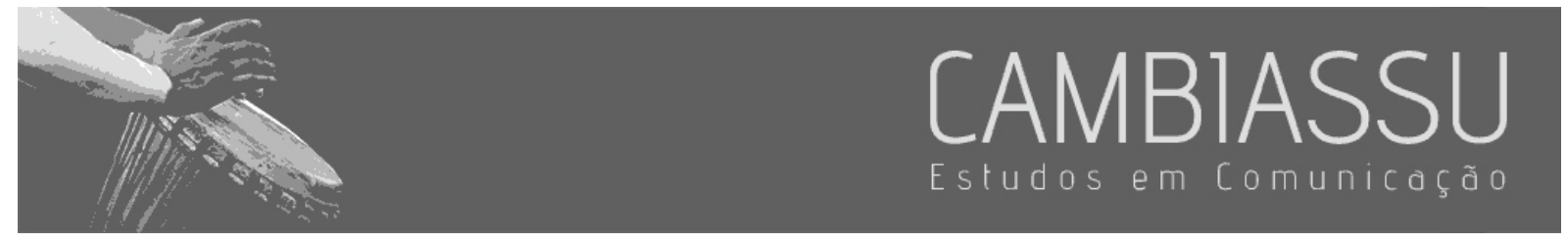

seu irmão a deixar o local antes da chegada da viatura. Após uma intensa discussão em que CJ usa o panfleto do velório com a foto de Calvin para persuadir o irmão, a polícia chega até o local e os abordam para pegar suas identidades. Em sua defesa, Calvin fala com os policiais que não estão envolvidos no assalto da loja e nesse momento os oficiais se tornam ainda mais agressivos e forçam todos a se deitarem para serem algemados.

Figura 5 - QUINTA VISUALIZAÇÃO DA MORTE

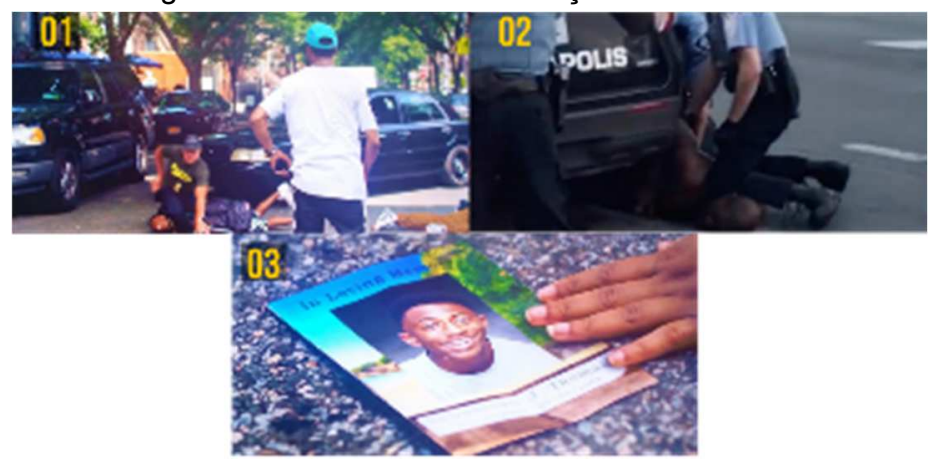

Fonte: $A$ Gente Se Vê Ontem (Stefon Bristol, 2019, Netflix) e reprodução do G1 -Site de Notícias.

No fotograma 01 da figura 5 (timecode: 01:12:47), vemos que o policial imobiliza Sebastian colocando o joelho em seu pescoço e apoiando o peso do seu corpo em direção ao solo - o que obviamente estava asfixiando o garoto. Ao lado, no frame 02, faço questão de trazer às nossas vistas, com intenção comparativa, a imagem em que o policial Derick Chauvin semelhantemente realiza o mesmo golpe contra o jogador de futebol americano, George Floyd. Por um instante, o golpe aplicado em Sebastian chega a matar seu futuro. Isso pode ser observado no frame 03 da imagem acima (timecode: 01:12:19), que constitui um plano de câmera subjetiva simulado a visão de Calvin. Ao ver que o panfleto ganha o rosto de Sebastian, Calvin entende que aquele objeto é ligado ao futuro e toma a decisão de se levantar para que de alguma forma impedisse aquela morte. Ao se levantar, Calvin coloca a mão no bolso para tirar seu celular e filmar a ação policial com o objetivo de gerar provas ou acanhar os oficiais. Mas ao mesmo tempo, a cena possui um tom de auto sacrifício, visto que a ação de Calvin o coloca na posição de alvo dos policiais. 


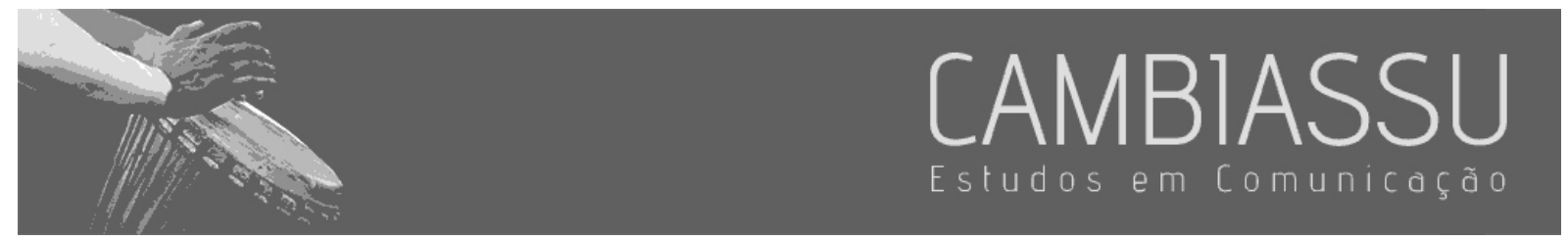

Figura 6 - SEXTA VISUALIZAÇÃO DA MORTE

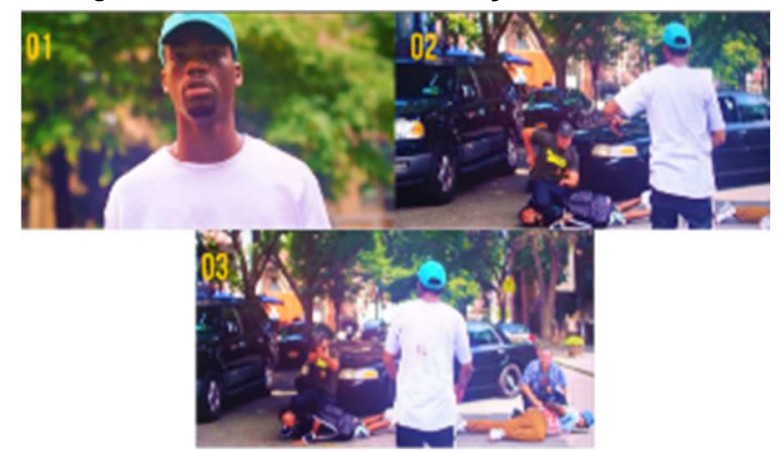

Fonte: A Gente Se Vê Ontem (Stefon Bristol, 2019, Netflix).

O frame 01 da figura 6 (timecode: 01:12:50) nos mostra o momento em que o garoto se levanta do chão ficando em frente aos policiais. O padrão de zoom in se repete. O movimento feito por Calvin coloca seu corpo inclinado para frente, o que reforça a interpretação de um possível ato de sacrifício. Em 02 (timecode: 01:12:47) podemos ver que ele retira o celular do bolso e aponta para os policiais. Já no frame 03 (01:12:55), voltamos a ter a presença do corpo marcado de sangue e pela primeira vez vemos o alvejamento acontecer sem nenhuma outra escolha de linguagem para encobrir a situação. A morte de Calvin apresentada na viagem 04 é a mais literal que encontramos no filme.

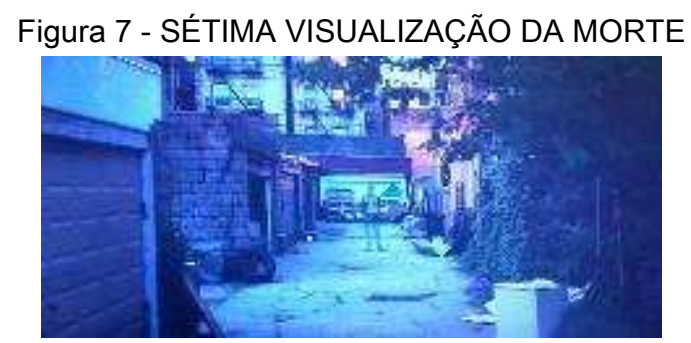

Fonte: A Gente Se Vê Ontem (Stefon Bristol, 2019, Netflix).

Por fim, temos a última cena de morte, que se faz presente, aproximadamente, em 01:14:22, como vemos na imagem acima. A cena em questão é a reconstrução do momento em que CJ parte para a quarta viagem no tempo com a ajuda do irmão e o deixa no presente. Depois que ela salta no passado, o garoto se torna translucido até desaparecer totalmente. Essa espécie de flashback é posicionada na montagem logo após a cena de morte que analisamos acima, o que interpretamos como a forma de mostrar que aquele tempo possui uma ligação com o passado, mas também com as 


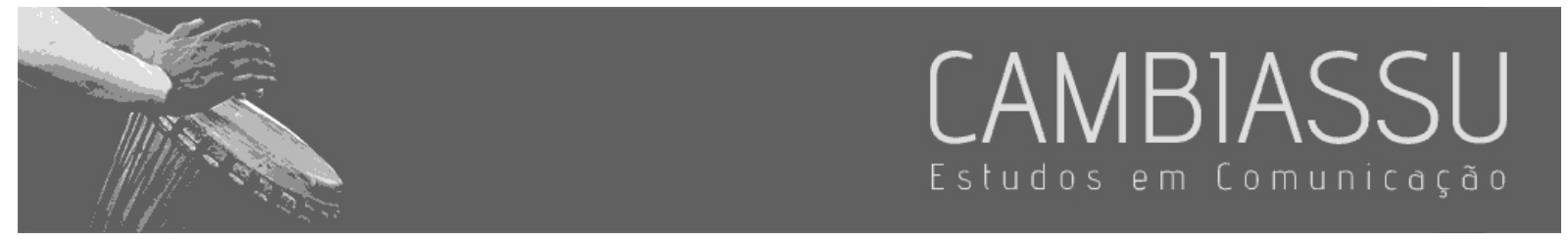

escolhas do presente, pois, segundos depois de CJ partir, seu irmão já havia morrido novamente. Este ponto evidencia as conexões temporais entre esses dois momentos do filme.

\section{Conclusões}

Por mais que a forma óbvia de dar imagem à morte seja conjurar o morto, em $A$ Gente Se Vê Ontem (2019) vemos outros modos de enunciá-la. O filme tem em sua característica utilizar a ausência do corpo para dizer sobre a morte. Ele substitui essas imagens por estratégias de narração sonora (disparo), pela interpretação do elenco (sentimento da perda) e pelo uso de efeitos visuais (panfleto do velório e desaparecimento de Calvin na última cena). Mas há momentos em que os signos que remetem a violência e morte, como o sangue no corpo, o corpo ao chão e os olhos fixados abertos, são convocados nos momentos de maior tensão. Há um flerte entre estratégias de acobertar e descortinar o contato com o morto. Isso permite que a história seja conduzida de forma mais palatável, evitando desconforto e angústia no espectador.

A morte também aparece no filme como um elemento de temporalidade quando vemos que as conexões entre futuro, passado e presente ora são diretamente ligadas e noutras são oscilantes. Essa ligação direta pode ser observada quando Sebastian morre na sequência de seu passado e quando Calvin desaparece depois da partida de sua irmã. Já a oscilação pode ser observada nos seguintes pontos: a) na forma com que o panfleto se torna um objeto fora do tempo, capaz de assumir em qualquer instante a imagem de quem fosse morto no dia $04 / 07$; b) pela maneira material que a versão do Sebastian do futuro morre, pois se seu passado foi apagado, como seu corpo físico ainda resiste para sofrer as consequências do tiro e simplesmente não desaparece?

Vimos que o filme apresenta, ao todo, sete momentos em que a morte pode ser visualizada, mesmo que na forma de suposição ou em condições efêmeras. As variadas estratégias narrativas utilizadas no filme corroboram para a construção da ideia de um mundo necropolítico. Essas mortes 


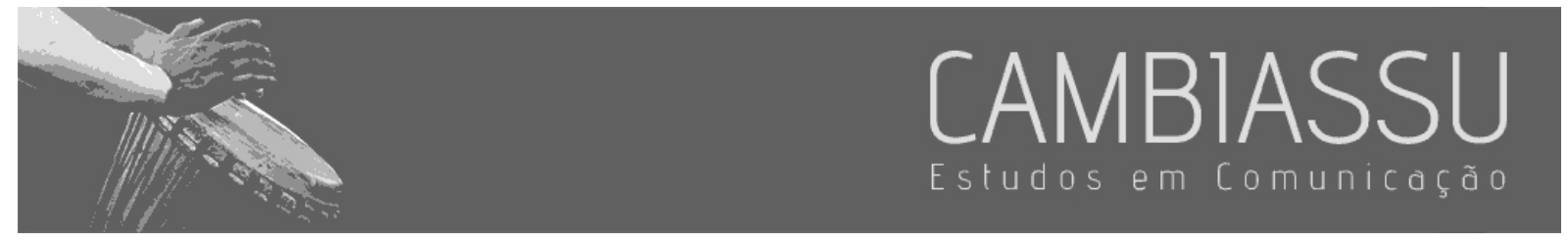

são as responsáveis pelas ações que levam às voltas no tempo - os principais acontecimentos da história. A narrativa do filme, em outros termos, os seus encadeamentos de sequências, depende da permanência da morte de uma pessoa negra para se sustentar, efetuando possíveis representações e interpretações para os conceitos de necropolítica e wake-work.

Assim como a morte aparece como um elemento de continuidade, a não aceitação/insurreição perante o genocídio emerge como uma cartografia de in/sobrevivência negra diaspórica. Dado que na cena final do filme, CJ realiza sozinha outra tentativa de impedir a morte, da qual não é mostrado o resultado, vemos que a persistência é performada até os últimos segundos da narrativa. É através de seu esforço mental e físico que CJ e Sebastian gastam suas energias para romper a crise temporal causada pelo homicídio de Calvin. A interrupção da vida negra jovem se configura como o próprio epicentro da catástrofe temporal provocada pelo racismo e pela necropolítica.

Sem respostas concretas e com o artifício da ficção, a dupla busca a mesma justiça que milhares de pessoas que perderam seus familiares de formas semelhantes tentam encontrar. Concluo que a narrativa evidencia uma luta que é contínua, cansativa, mas, sobretudo, apresenta-se como um ponto de apoio e esperança utópica para que o antirracismo não pare enquanto consertar os infortúnios do passado for possível. Seguimos!

\section{Referências Bibliográficas}

ABRIL, Gonzalo. Análisis crítico de textos visuales. Madrid: Editorial Sintesis,2007

ABRIL, Gonzalo. Tres Dimensiones del Texto e de la Cultura Visual. Revista Científica de Información y Comunicación, Sevilla, v. 9, n. 1, p. 15-35, dez. 2012.

ABRIL, Gonzalo. Cultura visual: de la semiótica a lo político. Madrid: Plaza y Valdés, 2014

ALMEIDA, S. L. de. Racismo estrutural. São Paulo: Editora Jandaíra, 2019. 264 p.

ALZAMORA, Geane. Textualidades Midiáticas. Belo Horizonte: PPGCom/UFMG, 2018. p. 103-112.

ESHUN, K. Moviment capture (interview). Ponto Virgulina: \#1 Afrofuturismo, Brasil, v. 1, n. 1, p. 216-244, 3 jun. 2020. 


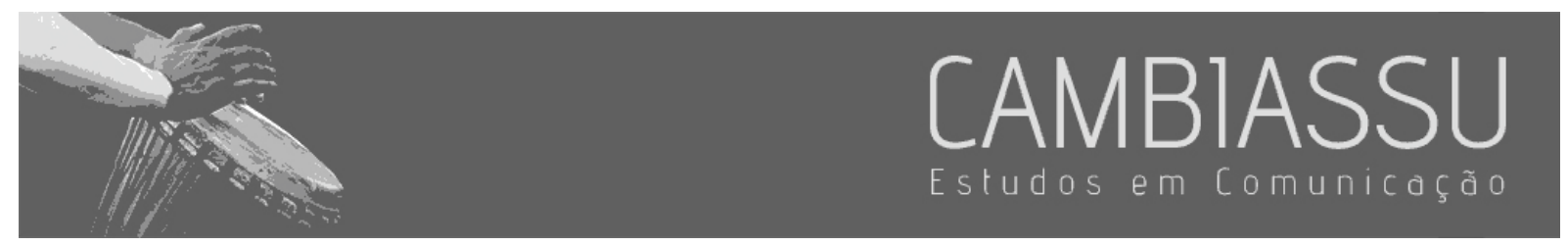

FREITAS, K.; SOUZA, E. P. O sacrifício de mulher negra no cinema afrofuturista - Distopia, morte e renascimento. In: CONFERÊNCIA INTERNACIONAL: ARTE, TECNOLOGIA E COMUNICAÇÃO. 2018, [S.I.]. Anais [...]. [S.I.]: Edições Cineclube de Avanca, 2018. p. 493 - 501.

HOOKS, B. Olhares negros: raça e representação. São Paulo: Elefante, 2019.

LEAL, B. Do texto à textualidade na comunicação: contornos de uma linha de investigação. In: LEAL, B.; CARVALHO, C. A.; ALZAMORA, G. Textualidades Midiáticas. Belo Horizonte: PPGCom UFMG, 2018, p. 1734.

LEAL, Bruno Souza; MENDONÇA, Carlos Camargos. Ver a elas: mulheres trans e dimensões políticas da cultura visual. In: LEAL, Bruno; CARVALHO, Carlos Alberto; ALZAMORA, Geane. Textualidades Midiáticas. Belo Horizonte: PPGCom/UFMG, 2018. p. 103-112.

MBEMBE, A. Crítica da razão negra. Lisboa: Antígona, 2014. 299 p. Tradução de Marta Lança.

MBEMBE, A. Políticas da inimizade. Lisboa: Antígona, 2017. 250 p. Tradução de Marta Lança.

SHARPE, C. In the wake: on Blackness and being. Durham: Duke University Press. 2016, 36p.

THE WASHINGTON POST. Fatal Force. 2020. Banco de dados de tiroteios fatais nos EUA. Disponível em: https://www.washingtonpost.com/graphics/investigations/police-shootings-database/ . Acesso em: 13 dez. 2021 